\title{
Mutations in SARS-CoV-2 genomes and future strategies
}

A R T I C L E I N F O

\section{Keywords}

SARS-CoV-2

COVID-19

Mutation

Public health

COVID-19 vaccine

Social distance

\section{To the Editor,}

The receptor-binding domain (RBD), which is a prominent target of vaccination sera and monoclonal antibodies, may be affected by genetic variation in SARS-CoV-2 progeny virions, potentially leading to pathogenic consequences. All three identified variants of concern, namely UK (B.1.1.7), Brazil (B.1.351), and Brazil (P.1), contain both the RBD and the N-terminal domain (NTD). Further N501Y variation on the RBD will increase the sensitivity of spike protein to the ACE 2 receptor, thereby improving viral binding. The RBD (receptor-binding domain), in conjunction with NTD, is the primary neutralizing target, promoting antibody production in response to antisera/vaccine. Recent findings reveal that a specific N501Y mutation significantly increases the affinity of RBD and angiotensin-converting enzyme 2 (ACE-2) approximately tenfold over the parental strain (N501-RBD) ${ }^{1}$ (see Fig. 1).

Almost all SARS-CoV-2 non-structural proteins (NSPs), including NSP2 and NSP3, as well as S protein, which contains RNA-dependent RNA-polymerase (RdRp), have undergone significant mutations. The $S$ protein, in general, has been identified as a critical determinant of SARSCoV-2 evolution, propagation, and toxicity, which may serve as a target for potential vaccine production. RdRp may potentially be an important target for antiviral medication development in the fight against COVID$19 .^{2}$

All viruses gradually mutate over time. Thousands of mutations have occurred in SARS-CoV-2 since the virus was first described a year ago. An overwhelming number of these variations are "passengers" and have little impact on the pathogen's behaviour and attitude. ${ }^{3}$ Occasionally, though, a virus may hit gold by undergoing a transformation that enables it to survive or replicate, and hence outcompete other variants via natural selection. This appears to be the case with the 202,012/01 version, which has spread across the United Kingdom (UK), as well as a comparable but distinct variety recently discovered in Africa. While the B.1.617 may be more transmissible, research indicates that existing COVID-19 vaccines will provide strong protection. Scientists are scrambling to understand what role B.1.617, the variant discovered in India, will play in future surges of COVID-19.

The spike genomes of viral strains in the UK and Africa vary, indicating that they are far more infectious. But the balance between what the virus does and what we do determines how rapidly it spreads. The condition changes more rapidly with the new variant, as constraints are eased and strengthened, leaving less room for failure in managing the distribution. Researchers are attempting to determine how the spike protein series, which is now being pushed, would affect vaccinations. The African version, which has several variants in the spike (S) gene, is of critical relevance. ${ }^{4}$

Vaccines have been known to be an effective public health intervention in combating infectious diseases. Current COVID-19 vaccinations seem to be safe, at least for the moment. Eventually, vaccines can be changed to be more close-fitting and reliable against this variant. Meanwhile, most of us agree that existing vaccines minimize infection/ transmission rates and serious disease against both the UK and African strains since the different mutations have not changed the $S$ protein shape to the point where the new vaccine-induced antibodies will not bind at all. However, in the long term, we may confront a scenario similar to flu, whereby different vaccines are developed and distributed annually. ${ }^{5}$ The concern is that the more strains we have, the more likely it is that the virus may be able to escape part of the vaccine, reducing its efficacy.

Not only does pathogen gene mutation increase the likelihood of SARS-CoV-2 spreading quicker in humans, but it also affects disease severity and detection using standard diagnostic methods.

It is also possible that the virus will become less susceptible to medicinal therapies that employ monoclonal antibodies to attack particular viral regions. ${ }^{5}$ SARS-CoV-2 infection results in polyclonal antibody responses directed against specific regions of the spike protein. To overcome natural or vaccine-induced immunity, the virus's spike protein must undergo significant mutations. Scientists are currently debating this possibility very seriously. ${ }^{6}$

Greater awareness about the effectiveness of vaccines must be created so that more and more people are encouraged to get vaccinated. ${ }^{7}$ With the potential for transmissible SARS-CoV-2 strains to spread globally, social media platforms and public officials should raise awareness by explaining the known health concerns and enhancing personal, procedural, engineering, and societal control methods that are 

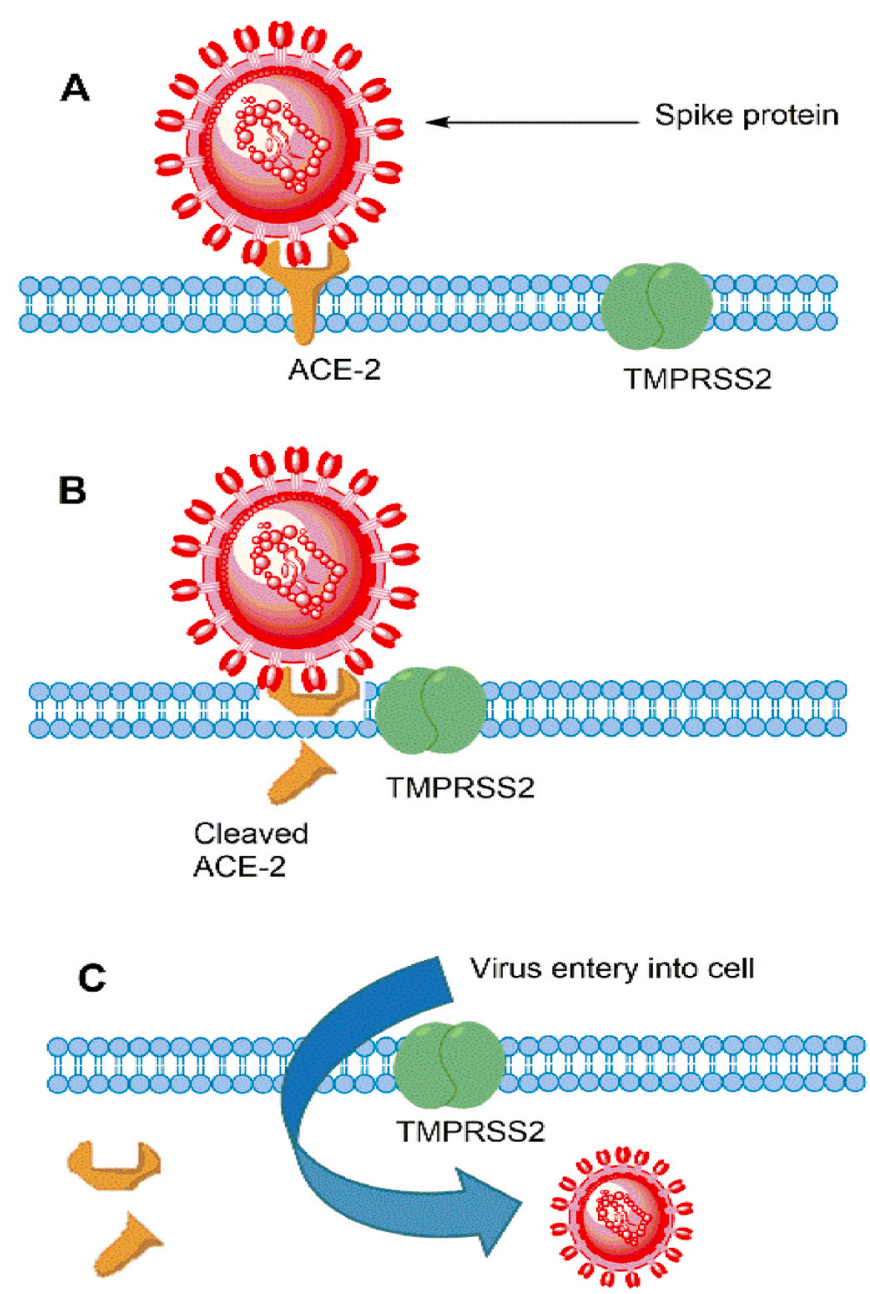

Fig. 1. Spike protein binds to ACE 2, activated spike protein binds to cleaved ACE2, and thus facilitates SARS-CoV-2 entrance.

known to be effective for reduced transmission. These include restricting social interactions, performing effective testing and tracking, conducting rigorous epidemic diagnosis and containment, assisting in the establishment of effective isolation and quarantine, and immunizing the populace. Furthermore, appropriate messages should be conveyed to educate the public about certain societal contexts and behaviours associated with a high transmission risk, as well as the need of continuing to implement mitigation measures. ${ }^{8}$

\section{Abbreviations}

COVID-19 CoronaVirus Disease

NTD N-Terminal Domain

RBD Receptor Binding Domain

B.1.1.7 UK

B.1.351 South Africa

P.1 Brazil
RdRp RNA dependent RNA-polymerase

FDA Food and Drug Administration

RT-PCR Reverse Transcription Chain Polymerase

SOPs Standard Operating Procedures

NAAT Nuclear Acid Amplification

\section{References}

1. Cascella M, Rajnik M, Aleem A, Dulebohn SC, Di Napoli R. Features, evaluation, and treatment of coronavirus (COVID-19). Available from: http://www.ncbi.nlm.nih. gov/pubmed/32150360; 2021.

2. Oude Munnink BB, Nieuwenhuijse DF, Stein M, et al. Rapid SARS-CoV-2 wholegenome sequencing and analysis for informed public health decision-making in The Netherlands. Nat Med. 2020;26(9):1405-1410. Available from: http://www.ncbi. nlm.nih.gov/pubmed/32678356.

3. Gómez J, Albaiceta GM, García-Clemente M, et al. Angiotensin-converting enzymes (ACE, ACE2) gene variants and COVID-19 outcome. Gene 2020;762:145102, Available from: http://www.ncbi.nlm.nih.gov/pubmed/32882331.

4. Weiss SR, Navas-Martin S. Coronavirus pathogenesis and the emerging pathogen severe acute respiratory syndrome coronavirus. Microbiol Mol Biol Rev. 2005;69(4): 635-664. Available from: http://www.ncbi.nlm.nih.gov/pubmed/16339739.

5. Abdullahi IN, Emeribe AU, Ajayi OA, Oderinde BS, Amadu DO, Osuji AI. Implications of SARS-CoV-2 genetic diversity and mutations on pathogenicity of the COVID-19 and biomedical interventions. J Taibah Univ Med Sci. 2020;15(4):258-264. Available from http://www.ncbi.nlm.nih.gov/pubmed/32837505.

6. Shen Z, Xiao Y, Kang L, et al. Genomic diversity of severe acute respiratory syndromecoronavirus 2 in patients with coronavirus disease 2019. Clin Infect Dis. 2020;71(15): 713-720. Available from: http://www.ncbi.nlm.nih.gov/pubmed/32129843.

7. van Dorp L, Acman M, Richard D, et al. Emergence of genomic diversity and recurrent mutations in SARS-CoV-2. Infect Genet Evol. 2020;83:104351. Available from: http //www.ncbi.nlm.nih.gov/pubmed/32387564.

8. Grubaugh ND, Hodcroft EB, Fauver JR, Phelan AL, Cevik M. Public health actions to control new SARS-CoV-2 variants. Cell. 2021;184(5):1127-1132. Available from: http ://www.ncbi.nlm.nih.gov/pubmed/33581746.

Nirav Nimavat

Community Medicine Dept., SBKS MIRC, Sumandeep Vidyapeeth, Vadodara, India

Shruti Singh

Department of Pharmacology, AIIMS, Patna, India

E-mail address: drshrutis@aiimspatna.org.

Amit Agrawal

Department of Paediatrics, Gandhi Medical College, Bhopal, India

E-mail address: agrawaldramit@yahoo.co.in.

Md Abdur Rafi

Rajshahi Medical College, Bangladesh E-mail address: abdurrafi007@gmail.com.

Benazeer Bhatti

Liaquat University of Medical and Health Sciences, Sindh, Pakistan E-mail address: benazeer.bhatti@live.com.

Ghanshyam Parmar

Department of Pharmacy, Sumandeep Vidyapeeth, Vadodara, India E-mail address: ghanstaurus22@gmail.com.

Ashish Shah

Department of Pharmacy, Sumandeep Vidyapeeth, Vadodara, India E-mail address: shah.ashishpharmacy@gmail.com.

* Corresponding author. E-mail address: nkniraj1529@gmail.com (N. Nimavat). 